Images dans le monde ibérique et ibéricoaméricain

$9 \mid 2016$

Innovations politiques et culturelles dans les pays andins

\title{
La Nación evanescente en Bolivia
}

Una confrontación entre globalización e identidades colectivas

Pamela Alcocer Padilla, Franco Gamboa Rocabado y Hugo Celso Felipe Mansilla

\section{(2) OpenEdition}

\section{Journals}

\section{Edición electrónica}

URL: http://journals.openedition.org/agedor/1121

DOI: 10.4000/agedor. 1121

ISSN: 2104-3353

Editor

Laboratoire LISAA

Referencia electrónica

Pamela Alcocer Padilla, Franco Gamboa Rocabado y Hugo Celso Felipe Mansilla, « La Nación evanescente en Bolivia », L'Âge d'or [En línea], 9 | 2016, Publicado el 01 marzo 2016, consultado el 07 mayo 2019. URL : http://journals.openedition.org/agedor/1121 ; DOI : 10.4000/agedor.1121

Este documento fue generado automáticamente el 7 mayo 2019.

L'Âge d'or. Images dans le monde ibérique et ibéricoaméricain 


\title{
La Nación evanescente en Bolivia
}

\author{
Una confrontación entre globalización e identidades colectivas \\ Pamela Alcocer Padilla, Franco Gamboa Rocabado y Hugo Celso Felipe \\ Mansilla
}

1 La Nación boliviana en tiempos del Estado plurinacional constituye un tema mencionado constantemente por los medios masivos de comunicación, pero poco estudiado con rigor analítico-crítico. Dentro de esta temática, el propósito central de nuestra investigación fue analizar la compleja disyuntiva en que se halla Bolivia en la actualidad, situada entre los procesos de globalización, por un lado, y la afirmación de las identidades colectivas que no se sienten partícipes de la civilización occidental, por otro.

2 En lo referente a las normativas de orientación, la sociedad boliviana se halla inmersa, por lo tanto, dentro del debate entre los principios universalistas (derivados del racionalismo de la tradición occidental moderna) y los valores particularistas (los que provienen de la propia herencia cultural pre moderna). El país ha estado casi siempre dividido, por lo menos en dos partes: aquella Bolivia de orígenes y valores indígenas versus el perfil de una Bolivia que aspira a ser parte del contexto mundial de la modernidad occidentalizada. Aunque recién en formación, esta última alternativa ha estado presente desde la fundación de la República; de hecho, la administración del mariscal Andrés de Santa Cruz (1829-1839) representa un intento temprano, pero fallido de modernización sistemática, sobre todo a partir de la estructuración de un ordenamiento jurídico que careció de su correspondiente armazón institucional. En aquella época, las preocupaciones por la Nación fueron sometidas a un vaivén conflictivo que marcaba el desprecio del legado cultural de los pueblos indígenas y donde predominaba una profunda discriminación racial, en contraposición a la imitación de un estilo de vida e institucionalidad venida de Europa. Estos choques caracterizaron a la cultural nacional por mucho tiempo.

3 Los problemas de investigación son estudiados en el marco de una narrativa analítica, que basada en aspectos y criterios cualitativos, intenta comprender las tensiones múltiples que se dan en la Bolivia actual. Los modos de proceder de la narrativa analítica han sido avalados por las prácticas actuales en ciencias sociales. Uno de ellos es el análisis de los discursos ideológicos, como ha sido desarrollado por varias corrientes de la politología y 
sociología críticas. Por ello uno de los objetivos específicos de este estudio es analizar los fenómenos ideológico-culturales del imaginario colectivo en la Bolivia del siglo XXI, a los que se atribuye una marcada singularidad pero mostrando, simultáneamente en una visión crítica, que dicho imaginario posee ciertos rasgos de continuidad con las herencias culturales anteriores. El telón de fondo es, como lo formuló Xavier Albó, la "confrontación entre la concepción más modernizante pero excluyente de la Nación-Estado en Bolivia y la reemergencia de los pueblos originarios, presentes pero invisibilizados en ella" ${ }^{1}$.

La principal hipótesis del trabajo afirma que los procesos de gobernabilidad del sistema democrático representativo ingresaron en una crisis impresionante mostrando, al mismo tiempo, los rasgos de una conducta intolerante manifestada por los partidos políticos entre 1985 y 2005, en términos de la no aceptación de "lo otro representativo", surgiendo así el carácter de una discriminación sistemática hacia los movimientos indígenas. Aquí emergió una contradicción importante porque la gobernabilidad negociada entre los partidos políticos del sistema democrático opacó los clivajes étnicos y minimizó los problemas irresueltos en relación con la construcción de la Nación boliviana. En consecuencia, el periodo de los "pactos gobernables" (1982-2005) se divorció del reconocimiento estructural de la diversidad multicultural que intentaba también acceder al poder. Esto fue convirtiéndose en el caldo de cultivo ideal para el reingreso con ímpetu del indianismo y para la fundación del nuevo Estado Plurinacional en el periodo 2006-2014, el cual tampoco ha estado exento de otra forma de crisis de identidades colectivas, fruto de las influencias que expresa la globalización económica y cultural donde Bolivia está inevitablemente inserta.

Para comprender el imaginario colectivo y sus dilemas centrales se analizó: (a) la amplia literatura que existe sobre esta temática; (b) las propuestas del indianismo radical (como han sido formuladas por Fausto Reinaga y sus seguidores); y (c) las deliberaciones de la Asamblea Constituyente (2006-2008). El propósito de este artículo es presentar los principales conflictos en torno al desarrollo de la Nación en Bolivia y establecer una explicación provisional acerca de los vínculos y las tensiones que existen entre el proceso de globalización (de carácter moderno, capitalista y universalista), junto a la preservación de valores autóctonos (a menudo de cuño particularista, colectivista y pre moderno), que contribuyen a la conformación de una identidad nacional propia, pero en constante reconfiguración, dentro de modelos sincretistas.

\section{Hacia una crítica del sentido común: la disyuntiva central y los mitos profundos del país}

6 Se puede aseverar que en la Bolivia del siglo XXI prevalece una especie de sentido común en torno al "colonialismo interno", el cual se expresa actualmente mediante las variantes de la teoría de la descolonización y enfoques afines. Un sentido común, por más extendido que esté y por más representantes doctrinales que tenga (la cara oculta de la modernidad), no se halla por encima de la crítica científica. Las variantes teóricas del mismo dan a conocer los anhelos postergados de una buena parte de la población boliviana y, por ello, denotan una gran legitimidad. Sin embargo, a menudo esta "consciencia subalterna", que a primera vista parece predominar en los pueblos indígenas pasa por alto los designios profundos de los sectores populares que dice reflejar, designios que incluyen postulados enteramente comprensibles, como alcanzar el nivel de vida de las naciones altamente 
desarrolladas (un alto ingreso per cápita) e imitar sus modelos de consumo y ocio. Aquí resalta la poderosa incursión de valores normativos de la globalización.

7 Surge, por lo tanto, un problema clásico: la brecha entre retórica y realidad, entre el discurso intelectual y político, de una parte, y la esfera de la praxis cotidiana, por otra. Este aspecto nos da luces en torno a las tensiones entre el campo de las ideologías, las esperanzas y las visiones del futuro - como las contenidas, así sea indirectamente, en las teorías de la descolonización -, por un lado, y el accionar diario de los habitantes del país, por otro.

8 Para ilustrar esta problemática podemos enfatizar la relevancia práctico-política de la modernidad entre los sectores poblacionales a los cuales están dirigidos los enfoques de la descolonización. Esos sectores tienen como meta normativa, a menudo de forma espontánea, una modernidad económica y tecnológica, que también a nivel mundial posee una fuerza considerable, de la cual la sociedad boliviana - en todos sus estratos sociales, grupos étnicos y opciones culturales - no se puede eximir, por lo menos parcialmente.

Si nos preguntamos, por ejemplo, cómo la tensión entre principios universales y valores particulares se engarza en Bolivia con la disyuntiva entre la preservación de la identidad nacional y los impulsos provenientes del proceso de globalización, entonces encontramos que la consolidación de la identidad nacional (y de las identidades sub-nacionales) tiene que ver, pese a las ideologías revolucionarias, con elementos de continuidad, es decir, de conservación de valores pre-modernos de orientación. Al mismo tiempo, el proceso de globalización presenta factores poderosos de cambio en los terrenos de la economía, la tecnología, los transportes y las comunicaciones, el diseño del ocio contemporáneo y hasta de la conformación de la estructura familiar.

10 Cuando la temática de la identidad irrumpe en el campo de las ciencias sociales bolivianas, lo hace en cuanto consciencia de una crisis ${ }^{2}$. Esto es enteramente comprensible. No ha habido generalmente una identidad aceptada y sólida, reconocida como tal por todos los sectores sociales importantes del país, sino más bien intentos repetidos y malogrados de crear identidades nacionales a partir de la acción - nunca sistemática - del Estado central ${ }^{3}$.

11 Sobre todo las corrientes revisionistas (nacionalistas, indianistas, indigenistas e izquierdistas en general) han afirmado que el resultado fue una identidad precaria, fragmentaria, dependiente, subordinada y subalterna que hasta llega a manifestarse bajo la forma de una máscara.

Desde una perspectiva realista, empero, debe considerarse la probabilidad de que casi todas las identidades nacionales a lo ancho del planeta han tenido problemas y dilemas similares. En el siglo XXI no existe ninguna identidad nacional absolutamente sólida y consolidada para siempre. Casi todas ellas se han formado, paradójicamente, al separase y diferenciarse de otras comunidades que también se concibieron a sí mismas en el pasado como identidades colectivas que anhelaban perdurar en el tiempo ${ }^{4}$. El recorrido histórico en varios países latinoamericanos es muy similar ${ }^{5}$.

13 Es posible que la identidad nacional, en sus comienzos (1825), haya sido una construcción jurídico-intelectual de aquellos políticos que crearon un país independiente sin preguntar a las mayorías nacionales si estaban de acuerdo con ello. Pero como pasa a menudo, la identidad nacional se ha ido consolidando paulatinamente, de acuerdo a un principio conocido en las ciencias sociales como la inercia cultural: lo que se repite a través de los hechos llega a adquirir una fuerza normativa tal que, si dura mucho tiempo, tiene una 
gran influencia en la configuración de sentimientos e imaginarios colectivos ${ }^{6}$. En el caso boliviano, $\mathrm{y}$ en lo referente a una identidad nacional, pese a todos los problemas y las carencias, podemos detectar un resultado que no es despreciable y que ha demostrado ser bastante sólido.

La pluralidad de opciones identitarias estuvo desde los inicios del siglo XX hasta hoy en el centro de los debates, pero también la idea de que las tendencias favorables a las diferencias no deberían obligar a los ciudadanos y a los grupos a definirse sólo en términos étnicos, los cuales no siempre determinan y configuran el núcleo de la vida cotidiana y de los sentimientos íntimos de los ciudadanos ${ }^{7}$. Esta concepción se ha revalorizado en el presente, pues toda sociedad urbana en proceso de modernización, sometida a procesos migratorios de distinto tipo, interconectada con el mundo y dependiente de los logros contemporáneos de la ciencia y la tecnología, atribuye un valor decreciente a la identificación con la etnia de origen, al hogar de los padres, la infancia y la juventud (en sentido sociocultural), a las pautas normativas de comportamiento de alcance limitado y a fenómenos como la confesión religiosa y las lealtades regionales.

El debate sobre esta temática destaca la idea de una ansiada Edad de Oro propia, exenta de fenómenos de explotación, de prácticas discriminatorias y de las alienaciones modernas. Así se fundamenta e ilumina la concepción de una meta normativa a la cual quieren llegar varias corrientes del indianismo ${ }^{8}$. Este es una porción básica, asimismo, del imaginario popular: los agravios y las grandes penurias de la mayor parte de la población habrían empezado con la colonización española. Tal explicación puede tener, por supuesto, su cimiento de amarga verdad, pero su repetición continua, vinculada a la visión embellecida de la época prehispánica, conforma uno de los mitos profundos del país. El mito, en este sentido, es un componente central para forjar las identidades indígenas en Bolivia, llenas de remembranzas trágicas del pasado y con el anhelo vigoroso de estar a tono con la contemporaneidad modernizante.

\section{La importancia actual del pensamiento de Franz Tamayo y Fausto Reinaga}

16 "Lo arcaico", dice un teórico de la de colonialidad como Javier Sanjinés, "no es lo caído en desuso, sino lo profundo". Este fue también el punto de partida de Franz Tamayo. Esta compresión, que tiene fuertes rasgos hermenéuticos, es asimismo, diferente de la explicación analítica de causas y efectos que prevalecen en las ciencias naturales. Al penetrar en las culturas "ajenas", nos percatamos de sus diferencias fundamentales y del pluralismo axiológico que es una de las características del mundo del Hombre, pluralismo que no admite una jerarquía construida con una gradación discriminatoria de valores. Aunque recién ahora hemos tomado plena consciencia de este punto. Las discusiones sobre estos temas, llevadas a cabo en terminologías que nos parecen anticuadas, poseen una larga existencia en el país.

En Bolivia se dio desde el siglo XIX una rica tradición consagrada a la vieja pregunta por el destino y la vocación de esta Nación, tradición encarnada por nuestros grandes ensayistas e historiadores que se han dedicado a cuestiones devenidas entre tanto clásicas, como los modelos adecuados de ordenamiento social, los vínculos complejos con los países altamente desarrollados y el futuro de la región ${ }^{10}$. Estas indagaciones, que comenzaron con Manuel José Cortés y Gabriel René Moreno, han sido frecuentemente 
arduas y hasta dolorosas, conformando algunas de las porciones más notables y controvertidas de la cultura boliviana y latinoamericana ${ }^{11}$. La discusión políticointelectual más o menos sistemática sobre la identidad nacional empieza, sin embargo, algo más tarde, cuando el país se embarca en el camino de la modernización según parámetros occidentales, y cuando en Bolivia surge un importante grupo de pensadores que se consagra intensamente a esta temática, como fueron los casos de Alcides Arguedas ${ }^{12}$ y Franz Tamayo ${ }^{13}$ en las primeras décadas del siglo XX. El debate implícito entre Arguedas y Tamayo, visto como tal en un brillante estudio de Josefa Salmón ${ }^{14}$, puede ser considerado como la primera confrontación manifiesta entre un universalismo liberal cosmopolita y un particularismo nacionalista de corte telúrico. Por esta razón, dicha controversia tiene una notable vigencia hasta hoy, puesto que representa posiciones que, con algunas reservas y modificaciones, se han mantenido hasta el presente.

El gran logro de Tamayo es haber puesto al indígena como sujeto de la historia y haber superado esa poderosa preconcepción que lo mantenía como mero objeto de políticas públicas, por más bien intencionadas que estas hayan sido, como fue el caso de las reformas educativas. Tamayo crea otra imagen social boliviana, afirma Josefa Salmón, según la cual la "unidad social" de la Nación estaría asentada sobre la psicología del carácter nacional indígena", algo único en América Latina ${ }^{15}$ y retomado por las teorías de la descolonización.

Otro motivo importante para estudiar a Tamayo es el esbozado por el precursor del indianismo, Fausto Reinaga, para quien en la Creación de la pedagogía nacional "se halla el pensamiento explosivo de la Revolución India que se avecina" ${ }^{16}$. Continúa Reinaga: "El valor de Tamayo no se halla en su intervención política, ni en su obra poética [...]. Su valor está en su pensamiento panfletario y su verbo de fuego" ${ }^{17}$. Reinaga considera a Tamayo como el precursor mesiánico del resurgir autóctono: "La esencia del pensamiento de Tamayo es india, no chola y menos ibérica"18.

Tamayo elogia las virtudes de persistir con respecto a la propia identidad. Celebra la resistencia de los indígenas frente al medio natural y a los avatares históricos, alabando el aislamiento cultural y político de los mismos. La teoría vitalista de Tamayo se parece a aquellas doctrinas que en la primera mitad del siglo XX se consagraron a divulgar la lucha eterna de los pueblos contra enemigos perpetuos, a enaltecer las identidades nacionales inmutables, a cantar el amor al colectivismo y a desdeñar todo esfuerzo racional y democrático. No es necesario mencionar los resultados de esas doctrinas en la praxis social y política, que culminaron en diversas variantes del totalitarismo, llegando asimismo a convertirse en un tipo de paternalismo. Para Tamayo, dicho paternalismo se complementa con una actitud básicamente autoritaria, lo que es muy usual en el mundo andino. El autor cantó las glorias del imperio incaico y pasó por alto los privilegios y abusos de las élites y de los poderosos de ese imperio. Supuso que era algo "natural" la conformación de jerarquías privilegiadas y también la conquista, el sometimiento y la explotación de otros pueblos indígenas.

21 En general, la obra tamayana está destinada a despertar emociones profundas y en realidad confusas, pero no a inspirar análisis de temas concretos y menos a motivar políticas públicas específicas. De esta manera, en Tamayo se desliza la intención de contemplar las fuerzas de la Nación, no a partir de sus reales posibilidades de cambio, sino a partir de una creencia de carácter religioso y contemplativo fundada en la cultura.

Mediante el poder sugestivo de su prosa, Tamayo expresó algunos prejuicios, extremadamente populares, que ya eran fuertes en su tiempo y que hasta hoy no han 
perdido nada de su vigor. El mito principal se manifiesta en la creencia de que la historia se reduce a una lucha maniqueísta entre los buenos, los indios explotados por un régimen de dominio inicuo y cruel, y los malos, los descendientes parasitarios de los españoles, taimados e hipócritas, incapaces de generar un verdadero progreso para la Nación.

No hay duda de que Tamayo detestaba los fenómenos de mestizaje y aculturación, los procesos de intercambio y adopción de ideas, bienes y costumbres que configuran una buena parte de la historia universal, y una de las más fructíferas: la modernización en el terreno de la educación sin ningún tipo de influencias de corte cultural, tradicional y ancestral, aunque el permanecer cerrado y aislado en el propio modelo civilizatorio conduce habitualmente al estancamiento y la decadencia. Como muchos seguidores de teorías similares, Tamayo rechazaba, en el fondo, las ideas del racionalismo y la Ilustración, los derechos humanos, la democracia contemporánea, la institucionalización de los procesos políticos y el Estado Derecho. El orden social moderno, urbano y abierto al mundo no era de su agrado.

El trabajo teórico e ideológico de Reinaga condensa simultáneamente las esperanzas y los prejuicios de grandes sectores poblacionales. Es decir: combina vigorosos elementos de preservación de lo pasado y conservación de pautas normativas de carácter pre moderno, por un lado, con la aceptación tácita de las metas normativas occidentales en el campo técnico y económico, por otro. La tensión entre los principios universales de la cultura globalizadora y los valores particulares emerge claramente cuando Reinaga, ya en 1969, identificó los cuatro elementos de la civilización occidental que debían ser radicalmente impugnados y eliminados porque esclavizaban a los indios sudamericanos: "el derecho romano, el código napoleónico, la democracia francesa y el marxismo-leninismo" ${ }^{19}$. La crítica del mundo colonial en particular y del occidental en general, iniciada por Reinaga y continuada, en muchas vertientes y variantes por las teorías de la descolonización y enfoques afines, es muy instructiva para comprender una de las dimensiones principales del proceso sociopolítico que vive Bolivia desde comienzos del siglo XXI. Los escritos de estas tendencias nos ayudan a entender las expectativas de importantes sectores sociales, como los urbanos de origen indígena y de urbanización reciente, contribuyendo, asimismo, a separar la noción de indigenismo (y las posibles políticas públicas vinculadas con éste) del concepto de indianismo (y las políticas públicas que supuestamente podrían extraerse de esta concepción).

En el núcleo del pensamiento reinaguista se encuentra la suposición de que hay una esfera casi sagrada, donde florecen las esperanzas y los sueños más sentidos de la sociedad, sus concepciones morales y religiosas y sus recuerdos del pasado glorioso. Esta esfera se acerca al campo de lo divino y por ello no puede ser comprendida - o descrita adecuadamente sólo mediante esfuerzos racionales. Lo sagrado es el espacio donde se dan los sentimientos que también animan poéticamente toda la obra de Reinaga: el amor, el altruismo, la confianza y la espontaneidad en las relaciones humanas, el terreno de la solidaridad inmediata entre los hombres y la amistad sin cálculo de intereses, pero también el lugar de las utopías sociales, la cólera revolucionaria y la violencia política ante las injusticias históricas. Aquí no tienen cabida las intermediaciones institucionales, ni las limitaciones impuestas por leyes y estatutos. Ya que esta esfera posee una dignidad ontológica superior en comparación con las otras actividades y creaciones humanas, a ella no se puede aplicar una reflexión que analice la proporcionalidad de los medios (por ejemplo: políticos o institucionales) o la adecuación instrumental de medidas con 
respecto a fines, pues estos últimos estarían más allá de todo esquema analíticoracionalista.

Los valores de orientación de esta esfera son "puros", en el sentido de que su vigencia no depende de mediaciones, las que siempre traen consigo un factor de distorsión y engaño, una posibilidad de falseamiento y ventajismo. De acuerdo con esta reflexión, la violencia revolucionaria tiene ese carácter de pureza y tampoco puede ser juzgada por el mezquino cálculo de proporciones. El racionalismo no sería parte de la verdadera esencia de la nación india y la Bolivia realmente digna, compenetrada de un carácter original gracias al pensamiento indio.

Las revoluciones genuinas, por lo tanto, tendrían un derecho histórico superior frente a toda crítica proveniente del liberalismo racionalista. Para Reinaga, hay que atribuir a la esfera de la moralidad y el altruismo una dignidad preferente, por encima del campo de la institucionalidad (administración estatal, Poder Judicial, fuerzas de orden público, etc.). Este último terreno concita en Reinaga casi siempre un marcado sentimiento de desconfianza y desprecio, pues es considerado como el lugar privilegiado de las patologías sociales como la discriminación racial. En cambio, parece decir, los factores asociados al ámbito de los sueños y anhelos más caros de la comunidad disfrutan de las cualidades de pureza, auto-referencialidad y hasta sacralidad. Estos aspectos no están, afortunadamente, sometidos a los principios de rendimiento, eficacia y proporcionalidad; no prevalece en esta esfera el detestable debate de intereses. En esta última se encuentra, en cambio, el potencial de nuevas concepciones, obviamente revolucionarias, acerca de la moral y la política. De ahí hay sólo un paso para pensar que la violencia revolucionaria, al ser una meta por derecho propio, se puede convertir en sagrada.

El debate en torno a los fundamentos aceptados a priori - a veces pre lógicos - de esta doctrina, es relevante porque una descolonización bien concebida y ejecutada, es vista por algunas corrientes radicales como la esencia del indianismo correctamente entendido ${ }^{20}$. El retorno a la "verdadera patria" sólo puede ocurrir mediante la "destrucción de los estados occidentales vigentes en la actualidad", lo que significaría "volver a la edad dorada de nuestros antepasados", a ese "paradigma ancestral", que es el "reencuentro de nosotros con nuestros antepasados" 21 . Aquí tenemos uno de los núcleos de toda la problemática: las tendencias indianistas militantes no han podido construir una meta normativa plausible para el futuro, que incluya elementos insoslayables de la civilización occidental moderna, y se refugian más bien en un "paradigma de la vida", que es concebido explícitamente como el retorno a la Edad de Oro de los antepasados, la cual pasa a conformar el modelo indiscutido del futuro.

Iván Apaza Calle, que se considera el sucesor ortodoxo y autorizado de Fausto Reinaga ${ }^{22}$, describe el conflicto entre el anhelo por la dignidad y por el reconocimiento, que ciertamente prevalece todavía en el seno de las comunidades indígenas bolivianas, y las dificultades de su satisfacción en un medio que se moderniza aceleradamente, es decir, que evoluciona según los parámetros de los Otros, dentro de la civilización occidental. Aquí radica la importancia de estos autores y sus visiones ideológicas, las cuales articulan una temática de alto valor emocional y por ello mismo es muy importante para las comunidades involucradas.

Las concepciones de Reinaga representan sin duda el dolor colectivo de la discriminación y la colonización, y por lo tanto son muy legítimas y válidas, pero no son posiciones democráticas ni pluralistas ${ }^{23}$. El estudio del reinaguismo es importante aún hoy porque algunas de sus posiciones han permanecido con notable persistencia en el imaginario 
popular boliviano, por ejemplo: la política es considerada como un juego de suma cero, mientras que la organización social y ética del ámbito prehispánico es vista como la meta normativa de un posible futuro luminoso, la ansiedad postcolonial y el menosprecio del pluralismo ideológico como sutil política imperialista de dominación ${ }^{24}$.

Esta es una "mística de la tierra", como la denominó Guillermo Francovich ${ }^{25}$, que no está en condiciones de definir claramente esas esencias prístinas y profundas, ni tampoco de describir adecuadamente cómo era la realidad fáctica de la Edad de Oro. En un paralelismo sintomático con los pensadores indianistas y con los ideólogos de la descolonización en la actualidad, los teluristas dan un salto hacia adelante y como metas normativas de las políticas actuales pasan a proclamar la necesidad del regreso a las esencias incontaminadas del pasado prehispánico: el mundo auténtico de los pueblos originarios. En este marco se establece el carácter paradigmático de la Edad de Oro, modélico y ejemplar hasta el siglo XXI; sin embargo, este postulado parece ser más una invocación muy sentida y emotiva, ya que no está respaldado por datos históricamente verificables y confiables.

Lo más probable es que el retorno a la Edad de Oro esté pensado solamente como una serie de compensaciones por la dignidad perdida, es decir como la consecución de actos simbólicos y gestos casi esotéricos de muy poca relevancia práctica, aunque se puede argumentar que los ajenos a esta cultura ofendida no pueden comprender el alcance y la verdadera significación de dichos actos y gestos. De todas maneras: llama la atención la desproporción entre la intensidad del sentimiento de reivindicación histórica, por un lado, y la modestia de los bienes simbólicos que crearían esa satisfacción compensatoria, por otro. Parece estar claro que las masas indígenas no se encuentran dispuestas a resignarse con ese tipo de reconocimiento simbólico y restauración mítica, sino que esperan lograr los frutos de un desarrollo técnico-económico muy similar a lo ya conseguido en los países de la vilipendiada civilización occidental. Esto es una clara declaración programática contra la modernidad, compartida por numerosos pensadores de la época, pues la vida de las grandes urbes, regida por el principio de eficacia y rendimiento, sería, en el fondo, un orden social insoportablemente complejo e insolidario.

Hoy en día, la importancia del pensamiento de Fausto Reinaga reside, entre otros aspectos, en su temprana crítica a la racionalidad instrumental, que es una de las manifestaciones del racionalismo occidental. Aunque esta crítica era conocida en ambientes intelectuales desde hace un siglo mediante Max Weber, no se puede negar a Reinaga el haber formulado, de manera totalmente autónoma, una versión muy interesante de la misma a través de sus observaciones, comparaciones e intuiciones, es decir mediante sus análisis y también por medio de sus corazonadas.

Ya en 1978 llegó a la conclusión de que la guillotina de la Revolución Francesa y la hoz y el martillo de la Revolución Soviética, eran de igual modo productos genuinos y diabólicos de la diosa Razón. En forma similar a la Escuela de Frankfurt, Reinaga sostiene que la Razón se "asesina a sí misma" y tiene la originalidad y la valentía de incluir a los experimentos socialistas de entonces dentro de los magnos productos de la misma Razón occidental. También tempranamente este autor tuvo el mérito de señalar los efectos nocivos de la modernización en el campo del medio ambiente, proclamando la imperiosa necesidad de una convivencia amistosa con la Madre Tierra, aunque, lamentablemente, todas estas ideas nunca llegaron a ser formuladas de manera adecuada y transmisible para amplios sectores sociales. 
No hay duda de que la teoría de Fausto Reinaga y las escuelas sucesorias, como las doctrinas de la descolonización, han iluminado los lados perversos de la modernidad occidental, que no son pocos. Y lo han hecho para restablecer la dignidad menoscabada de los pueblos indígenas. En ambas líneas, estas concepciones representan, en el fondo, una respuesta comprensible (dentro de un cierto contexto cultural) al impulso modernizadorglobalizante de cuño mayoritariamente capitalista que hizo su aparición en gran parte de Asia, África y América Latina desde el siglo XIX, y de manera acelerada desde la segunda mitad del siglo XX.

\section{La reivindicación postmodernista del indianismo como nueva ideología de identidad nacional}

Uno de los hallazgos de nuestro proyecto de investigación tiene que ver con la notable continuidad entre el pensamiento de Franz Tamayo y los primeros enfoques indianistas (los de Fausto Reinaga), por un lado, y las actuales teorías de la descolonización, por otro. Esta continuidad ha sido rejuvenecida por las inclinaciones anti-occidentalistas y por los elementos relativistas propios de las doctrinas contemporáneas de carácter postmodernista, cuyo ejemplo más importante es la obra de Javier Sanjinés. Como dice este autor, se produce permanentemente "un ir y venir" entre el renacimiento de la memoria arcaica y el pasado mítico, por un lado, y las coerciones de la "azarosa vida moderna"26, por otro. Este aporte, claramente inspirado por la filosofía de Tamayo, puede ser considerado como un genuino manifiesto conservador, aunque la intención habría sido el mostrar una raíz posible para la revolución. Este enfoque está escrito en el lenguaje académico de la actualidad, postulando la fidelidad a un orden social arcaico porque este sería profundo y en armonía con la naturaleza, en detrimento del orden moderno urbano, que representaría una fuente artificial de corrupción y decadencia ${ }^{27}$.

Sanjinés da a entender que los fenómenos modernos, como la formación de la Nación cívica mediante la decisión consciente de los ciudadanos, representan algo superficial que no alcanza la dignidad ontológica de lo arcaico, de las estructuras comunitarias precoloniales y del modelo endógeno-indígena ${ }^{28}$. La democracia, en cuanto deliberación racional y abierta, constituiría un factor exógeno y moderno, por lo tanto, deleznable, insustancial y hasta frívolo. No tendría la calidad y la solidez de los valores de la tradición, que son la "promesa de la continuidad", "la fidelidad, la admiración y la gratitud" 29 . Sólo ellos evitarían "esa multiplicidad confusa de tendencias y aspiraciones que supone el libre albedrío individualista. Se trata, pues, de la fidelidad a una causa superior que supera las mudanzas del tiempo"30.

Las ideas generadas por Javier Sanjinés y otros de concepciones análogas, son muy importantes para clarificar una mentalidad posiblemente mayoritaria en el área andina, pero no son ideas que estén ahora en vinculación o confrontación con la realidad de la globalización y modernización que avanza raudamente en un mundo cada vez más pequeño e intercomunicado. La ausencia más notoria también se condensa en una ceguera respecto al papel de los medios de comunicación, instrumentos postmodernos que son, en definitiva, quienes cuentan, contarán y transmitirán lo que representa la Nación y el cosmopolitismo abierto. Tampoco estos medios visualizan a lo arcaico como parte de la identidad ancestral, sino como señal de infantilismo y nota extravagante para la fugaz anécdota histórica. 

empírico de vieja data: los campesinos, comerciantes, artesanos, trabajadores informales y artesanos de origen indígena se perciben a sí mismos como ciudadanos de segunda clase en su propio país, que casi siempre les ha brindado una "inclusión abstracta y exclusión concreta" ${ }^{33}$, como lo formuló Pablo Stefanoni. Son, evidentemente, promesas no cumplidas de ciudadanía plena, pues los discriminados perciben sólo una ciudadanía formal que los invisibiliza como grupo y los explota como individuos. Este tipo de exclusión ha cancelado tempranamente la búsqueda de una Nación boliviana como realidad efectiva de auto-identificación y solidez existencial como país. Para comprender esta compleja temática, podemos partir de este esquema: (a) Para casi todos los segmentos poblacionales, los adelantos y los valores normativos de la modernidad / globalización / occidentalización, sobre todo en los terrenos tecnológico, científico, económico, médico y comunicacional, son simplemente irrenunciables y, yendo más allá, son percibidos como algo natural, algo que le llega a todas las culturas, a algunas más pronto que a otras. (b) Las fronteras entre la defensa de lo propio / autóctono / comunitario y lo importado / occidental / individualista, son altamente porosas. La mayor parte de la sociedad boliviana traspasa esos límites cada día en su quehacer cotidiano, y no siente ningún problema de consciencia al hacerlo. En otras palabras: la población, incluyendo en primer lugar a los sectores indígenas, ha construido lentamente una solución sincretista, como es lo usual a lo largo de la historia universal.

41 El punto más significativo reside, no obstante, en la siguiente dimensión. Aunque en forma implícita, parece que los sectores no indígenas del país - y una parte considerable de las comunidades de origen indígena, pero ya de urbanización reciente - no pueden hallar fácilmente factores de identificación con la identidad indígena tal como está formulada por los autores más conocidos de las tendencias indianistas, en las teorías del colonialismo interno y en los enfoques de la descolonización. Dicha identidad la encuentran demasiado radical y cerrada a la comprensión de otras culturas, poco abierta al mundo globalizado de la actualidad y, sobre todo, anacrónica.

Para algunos sectores sociales, entonces, la identidad indígena se ve restringida a los signos externos: la destreza lingüística, la vestimenta y algunos usos y costumbres. Entonces surge la pregunta sobre si la identificación con el ámbito indígena es, bajo ciertas circunstancias, una especie de conveniencia política del momento, lo que se complementa con el postulado de cierta plausibilidad que asevera que la autoidentificación indígena sería una posición más emocional y política, antes que la representación fidedigna de una realidad insoslayable.

43 Es probable que esta etnicidad militante configure una ideología identificadora de los líderes y de las élites políticas de las etnias indígenas, y que sea mucho más débil en las masas de los campesinos y los habitantes urbanos de origen quechua y aymara. La mayor parte de la población indígena boliviana tiene otras preocupaciones cotidianas, centradas en la esfera laboral, y probablemente otros valores de orientación a largo plazo ${ }^{34}$, que se 
los puede designar sencillamente como la demanda de un mejor nivel de vida, imitando parcialmente los modelos del Norte, sobre todo en los aspectos técnico-económicos. Todos quieren aumentar su ingreso mensual, acceder a cómodas fuentes de trabajo y asegurar un salario que les permita consumir en gran escala los bienes materiales que caracterizan la vida cómoda de la clase media occidental.

En base a un amplio estudio empírico sobre esta temática, Porfidio Tintaya Condori llega a la conclusión de que la identidad aymara todavía está en construcción, expresada y recreada por identidades locales y personales, además de estar considerablemente influida por los movimientos sociales, los cuales son vistos como factores parcialmente exógenos con respecto a esa identidad no tocada por la occidentalización.

El renacimiento de la identidad indigenista tiene un porvenir ambiguo. Las comunidades rurales campesinas, por ejemplo, están cada vez más inmersas en el universo globalizado contemporáneo, cuyos productos, valores y hasta simplezas van adoptando de modo inexorable. Según los testimonios de dirigentes de la Confederación Sindical Única de Trabajadores Campesinos de Bolivia (CSUTCB) con quienes se habló para este estudio, en las ciudades intermedias y pequeñas de raíz rural, el bien más apreciado que simboliza un buen status social, es la presencia de una camioneta o un automóvil todo terreno cuatro por cuatro. Además, los propios habitantes aymara-campesinos comparan o miden su realidad con aquella del mundo occidental, y son ellos mismos quienes compilan inventarios de sus carencias, los que son elaborados mediante la confrontación de su propio mundo con las ventajas ajenas.

Todas las comunidades campesinas y rurales en la región andina se hallan desde hace ya mucho tiempo sometidas a los procesos de aculturación, mestizaje y modernización, lo que ha conllevado la descomposición de su cosmovisión original y de sus valores ancestrales de orientación. El futuro pertenece claramente a los modelos sincretistas. Un dato empírico registrado en encuestas y observaciones de campo, muestra que los pobladores rurales con mercados campesinos prósperos tienen acceso a servicios financieros como créditos bancarios, junto a un apreciable aspecto colateral que es el símbolo de prosperidad con bienestar económico.

\section{Conclusiones}

En el fondo muchas de las discusiones y los debates sobre los conflictos de las identidades colectivas se refieren a las formas de elegir una máscara en cuanto a la configuración de la identidad nacional en Bolivia. Esto tiene que ver con el logro o el fracaso por conseguir oportunidades iguales de participación. De esta manera, los dilemas de la identidad se expresan en los siguientes escenarios: (a) La máscara de una Nación como lógica contractual, desde la cual se diseminaron las ideas sobre homogeneidad mestiza y ciudadanía universal. (b) La máscara de la lógica territorial, donde el Estado constituía un eje de integración y la principal matriz de desarrollo socio-económico, convirtiéndose en el centro de la ideología nacional-populista. (c) La fachada de una lógica modernista donde Bolivia se acoplaba a las tendencias del desarrollo occidental europeizante y universalista. (d) La fachada de la lógica sincretista o de pluralidad intercultural, sobre todo a partir de la otorgación del voto universal y el surgimiento de la identidad campesina para dejar de lado las identidades étnico-indígenas, que luego acusaron de etnocida al Estado-Nación, mestizo y homogeneizador. (e) La máscara del reposicionamiento permanente de la Nación, sobre todo en los momentos de crisis para 
proteger y preservar la unidad, o el sentimiento de pertenencia como "todos somos bolivianos", que facilita la diferenciación del país respecto a otras naciones en el entorno de la globalización.

La discusión puede ser también filosófica para estimular el debate en torno a la Nación como invención existencial, es decir, como cemento social que permita reconocernos alrededor de una comunidad solidaria y con identidad política ante la existencia de otros Estados, culturas y naciones. Sin embargo, es aquí donde una vez más las identidades colectivas juegan el papel de múltiples máscaras que hacen del proceso político boliviano una efervescencia con choques permanentes.

La dinámica de conflictos entreteje las pugnas entre las exigencias por una gobernabilidad democrática, junto con las concepciones de nuevas élites indígenas donde se culpa al pasado colonial y la cultura española por toda la dinámica de explotación que sumió a los pueblos indígenas en una completa decadencia. En tanto que para las clases urbanas occidentales y cosmopolitas, el hilo conductor se encuentra ligado a la cultura euro-norteamericana global, donde el mestizaje representaría un centro de articulación deseable.

La búsqueda de una identidad nacional en Bolivia siempre ha confrontado las ambiciones de poder de las élites dominantes y las pugnas por visibilizar los esfuerzos del pluralismo étnico-cultural del país. Esta lucha tuvo un interregno de relativa estabilidad entre 1982 y 2003 donde el sistema de partidos de la democracia representativa logró sustituir los viejos debates en relación con la existencia de un Estado-Nación homogéneo y sus limitaciones, con una excesiva confianza en el liberalismo de mercado. Esto dio lugar a la marginación política de otras identidades colectivas, sobre todo aquellas que enarbolaron las ideologías indianistas junto con sus propuestas de autonomía y autogobierno.

51 Entre los principales hallazgos de este estudio se destaca que en el periodo denominado “pactos de gobernabilidad 1982-2005", el sistema de partidos fue negligente al no reconocer la incorporación de otro tipo de representaciones políticas. Pese a que la promulgación de la Ley de Participación Popular de 1993 suponía un equilibrio entre el Estado central y sus reformas descentralizadoras, la súbita elección de autoridades indígenas catapultó las exigencias por el reconocimiento de las culturas subalternas.

La Nación boliviana es una pretensión evanescente, tanto para los pueblos indígenas como para los sectores urbanos de clase media. En gran medida, los problemas del EstadoNación y las identidades colectivas sucumben ante la fuerza avasalladora de los valores derivados de la globalización (las normativas tecnológicas, por un lado, los efectos provenientes de la incorporación de Bolivia a los grandes circuitos internacionales del comercio, a través de la adquisición de bienes materiales por otro y, finalmente, las tendencias provenientes de la cultura moderna del ocio).

Las corrientes indianistas no han podido prescindir de toda esta influencia modernizante. Al contrario, ha surgido un proceso de adaptación de la misma con tintes autóctonos en los aspectos superficiales: entradas folclóricas y la preservación de ritos o creencias que suponen la esencia de una Bolivia profunda. Como en muchos lugares del mundo existe una cultura sincretista donde la influencia modernizadora se impone paulatinamente sobre los valores ancestrales.

La realización de una Asamblea Constituyente difundió la idea del reingreso en otra época más democrática y verdaderamente boliviana; empero, todo fue un anhelo inconcluso pues la Constituyente ahondó los conflictos étnicos y la lucha de clases, reforzando cierta 
fragmentación de visiones ideológicas en torno al futuro como país. Las ideologías indianistas y la propia democracia política presentan un divorcio respecto a la realidad donde persisten la pobreza y las desigualdades económicas. En el fondo, los problemas ideológicos de la nacionalidad o del Estado Nacional no significan una real preocupación para la existencia diaria de las grandes mayorías que solamente pretenden subsistir humanamente.

El planteamiento de un Estado Plurinacional en el periodo 2006-2014 es una nueva máscara que opera como instrumento de legitimación de un partido y un líder orientados hacia presunciones hegemónicas. La sociedad boliviana aún transita hacia la modernidad y va dejando atrás las tradiciones indígenas, para lo cual la disyuntiva entre ser boliviano o adoptar otras identidades originarias, termina siendo algo progresivamente superfluo. El crecimiento económico junto con el mejoramiento de las condiciones de vida, podrían ir apagando la disyuntiva en la medida en que Bolivia se encuentra confrontada con los requerimientos específicos para lograr un lugar en el mundo globalizado del siglo XXI.

\section{NOTAS}

1. ALBÓ Xavier, Prólogo, in SANJINÉS C. Javier, Rescoldos del pasado. Conflictos culturales en sociedades postcoloniales, La Paz, PIEB, 2009, p. XIII.

2. Cf. la obra precursora: OVANDO SANZ Jorge Alejandro, Sobre el problema nacional y colonial de Bolivia, La Paz, Juventud, 1984, p. 123-132.

3. Entre otros escritos cf. OBLITAS FERNÁNDEZ Edgar (comp.), La polémica en Bolivia. Un panorama vivo de la cultura de un país a través de las grandes polémicas, La Paz, s.e. 1997; MIRANDA PACHECO Mario (comp.), Bolivia en la hora de su modernización, México, UNAM, 1993; CAMPERO PRUDENCIO Fernando (comp.), Bolivia en el siglo XX. La formación de la Bolivia contemporánea, La Paz, Harvard Club de Bolivia, 2000.

4. MATO Daniel (comp.), Teoría y política de la construcción de identidades y diferencias en América Latina y el Caribe, Caracas, Nueva Sociedad / UNESCO, 1994; CASTRO-GÓMEZ Santiago, Crítica de la razón latinoamericana, Barcelona, Puvill, 1996.

5. LARSON Brooke, Trials of Nation Making: Liberalism, Race, and Ethnicity in the Andes, 1810-1910, Cambridge U. P., Cambridge, 2004; ZAPATA Claudia (comp.), Intelectuales indígenas piensan América Latina, Quito,UASB /Abya-Yala, 2007.

6. ARGUEDAS José María, Formación de una cultura nacional indoamericana (compilación de Ángel Rama), México, Siglo XXI, 1989.

7. Sobre la pervivencia de una identidad general boliviana pese a las corrientes pluri-identitarias, ver los testimonios contemporáneos mencionados en SALAZAR DE LA TORRE Cecilia, "Otredad y representación en la Asamblea Constituyente”, in ZUAZO OBLITAS Moira / QUIROGA SAN MARTÍN Cecilia (comps.), Lo que unos no quieren recordar es lo que otros no pueden olvidar. Asamblea Constituyente, descolonización e interculturalidad, La Paz, FES / fBDM, 2011, p. 21-68.

8. Para una descripción exhaustiva, pero fantasiosa de esa época, basada en los conceptos de "paraíso terrenal”, cf. REYNAGA BURGOA Ramiro, Tawantinsuyo: hoy y mañana, La Paz, Chitakolla, 1984.

9. SANJINES Javier, Recoldos del pasado.., op. cit., p. 191. 
10. CONDARCO MORALES Ramiro, Historia del saber y la ciencia en Bolivia, La Paz, Academia Nacional de Ciencias de Bolivia, 1978; VALENCIA VEGA Alipio, El pensamiento político en Bolivia, La Paz, Juventud, 1973; FRANCOVICH Guillermo, El pensamiento boliviano en el siglo XX, México, FCE, 1956; PRUDENCIO Roberto, Ensayos históricos, La Paz, Juventud, 1990.

11. BARNADAS Josep M., Gabriel René Moreno (1836-1908). Drama y gloria de un boliviano, La Paz, Altiplano, 1988.

12. SALMON Josefa, El espejo indígena. El discurso indigenista en Bolivia, La Paz, Plural 2013, p. 57-70.

13. Ibid., p. 70-77.

14. Ibid., p. 18.

15. Ibid., p. 42.

16. REINAGA Fausto, La "intelligentsia" del cholaje boliviano, La Paz, Ediciones Partido Indio de Bolivia, 1967, p. 50.

17. Ibid., p. 61.

18. Ibid., p. 63.

19. REINAGA Fausto, La revolución india, La Paz, La Paz, Ediciones del Partido Indio de Bolivia, 1969 , p. 15.

20. APAZA CALLE Iván, Colonialismo y contribución en el indianismo, La Paz/el Alto,Pachakuti/Awqa, 2011, p. 70-71.

21. Ibid., p. 76- 90 .

22. Ibid., p. 52-79.

23. GAMBOA ROCABADO Franco, "Bolivia y una preocupación constante: el indianismo, sus orígenes y limitaciones en el siglo XXI", in: Araucaria. Revista iberoamericana de filosofía, política y humanidades, Sevilla, vol. 11, № 22, julio-diciembre de 2009, p. 125-151.

24. GARCÉS V. Fernando, "De la interculturalidad como armónica relación de diversos a una interculturalidad politizada", in: David Mora (comp.), Interculturalidad crítica y descolonización. Fundamentos para el debate, La Paz, Convenio Andrés Bello / III 2011, p. 21-49.

25. FRANCOVICH Guillermo, El pensamiento boliviano en el siglo XX, México, FCE, 1956, p. 33.

26. SANJINES C Javier., Rescoldos del pasado... op. cit. (note 2), p. 2.

27. Ibid., p. 212.

28. Ibid., p. 168-169.

29. Ibid., p. 12.

30. Ibid., p. 12.

31. RIVERA CUSICANQUI Silvia, "Democracia liberal y democracia de ayllu", in TORANZO ROCA Carlos F. (comp.), El difícil camino hacia la democracia, La Paz, ILDIS 1990, p. 9-51.

32. STEFANONI Pablo, "Qué hacer con los indios...". Y otros traumas irresueltos de la colonialidad, La Paz, Plural, 2010, p. 10.

33. Ibid.

34. TINTAYA CONDORI Porfidio, Construcción de la identidad aymara en Janq'u Qala y San José de Qala, La Paz, Instituto de Estudios Bolivianos/UMSA/ASDI, 2008.

\section{RESÚMENES}

Este artículo analiza los conflictos y dilemas por los que atraviesa la sociedad boliviana, haciendo énfasis en el debate que existe entre los principios universalistas (derivados del racionalismo de 
la tradición occidental moderna) y los valores particularistas (los que provienen de la propia herencia cultural pre-moderna). El país ha estado casi siempre dividido, por lo menos en dos partes: aquella Bolivia de orígenes y valores indígenas, versus el perfil de una Bolivia que aspira a ser parte del contexto mundial de la modernidad occidentalizada.

Cet article analyse les conflits et les dilemmes qui traversent la société bolivienne, en mettant l'accent sur le débat qui existe entre les principes universalistes (dérivés du rationalisme de la tradition occidentale moderne) et les valeurs particularistes (qui viennent de l'héritage culturel pré moderne). Le pays a presque toujours été divisé au moins en deux parties: la Bolivie des origines et des valeurs indigènes, versus le profil d'une Bolivie qui aspire à faire parie du contexte mondial de la modernité occidentale.

ÍNDICE

Palabras claves: conflictos de identidades, Estado-Nación, identidades colectivas, globalización, modernidad, particularismo, universalismo

Mots-clés: conflits d'identités, État-Nation, identités collectives, globalisation, modernité, particularisme, universalisme

\section{AUTORES}

\section{PAMELA ALCOCER PADILLA}

Universidad Mayor San Andrés (UMSA), La Paz

\section{FRANCO GAMBOA ROCABADO}

Consejo Latinoamericano de Ciencias Sociales, Quito

\section{HUGO CELSO FELIPE MANSILLA}

Vicepresidente de la Academia Nacional de Ciencias de Bolivia 